Article

\title{
Anti-Oxidative Stress Activity Is Essential for Amanita caesarea Mediated Neuroprotection on Glutamate-Induced Apoptotic HT22 Cells and an Alzheimer's Disease Mouse Model
}

\author{
Zhiping Li ${ }^{1}$, Xia Chen ${ }^{1, *}$, Wenqian $\mathrm{Lu}^{2}$, Shun Zhang ${ }^{2}$, Xin Guan ${ }^{1}$, Zeyu Li ${ }^{1}$ and Di Wang ${ }^{2, *}$ \\ 1 Department of Pharmacology, College of Basic Medical Sciences, Jilin University, Changchun 130006, China; \\ zpli15@mails.jlu.edu.cn (Z.L.); jldxgx@126.com (X.G.); uclad@outlook.com (Z.L.) \\ 2 School of Life Sciences, Jilin University, Changchun 130006, China; luwq15@mails.jlu.edu.cn (W.L.); \\ zs1225643908@outlook.com (S.Z.) \\ * Correspondence: chenx@jlu.edu.cn (X.C.); jluwangdi@outlook.com (D.W.); Tel.: +86-431-8561-9799 (X.C.); \\ +86-431-8516-8646 (D.W.)
}

Received: 14 June 2017; Accepted: 24 July 2017; Published: 27 July 2017

\begin{abstract}
Amanita caesarea, an edible mushroom found mainly in Asia and southern Europe, has been reported to show good antioxidative activities. In the present study, the neuroprotective effects of A. caesarea aqueous extract (AC) were determined in an L-glutamic acid (L-Glu) induced HT22 cell apoptosis model, and in a D-galactose (D-gal) and $\mathrm{AlCl}_{3}$-developed experimental Alzheimer's disease (AD) mouse model. In $25 \mathrm{mM}$ of L-Glu-damaged HT22 cells, a 3-h pretreatment with AC strongly improved cell viability, reduced the proportion of apoptotic cells, restored mitochondrial function, inhibited the over-production of intracellular reactive oxygen species (ROS) and $\mathrm{Ca}^{2+}$, and suppressed the high expression levels of cleaved-caspase-3, calpain 1, apoptosis-inducing factor (AIF) and Bax. Compared with HT22 exposed only to L-Glu cells, AC enhanced the phosphorylation activities of protein kinase B (Akt) and the mammalian target of rapamycin (mTOR), and suppressed the phosphorylation activities of phosphatase and tensin homolog deleted on chromosome ten (PTEN). In the experimental AD mouse, 28-day AC administration at doses of 250, 500, and $1000 \mathrm{mg} / \mathrm{kg} /$ day strongly enhanced vertical movements and locomotor activities, increased the endurance time in the rotarod test, and decreased the escape latency time in the Morris water maze test. AC also alleviated the deposition of amyloid beta $(\mathrm{A} \beta)$ in the brain and improved the central cholinergic system function, as indicated by an increase acetylcholine (Ach) and choline acetyltransferase (ChAT) concentrations and a reduction in acetylcholine esterase (AchE) levels. Moreover, AC reduced ROS levels and enhanced superoxide dismutase (SOD) levels in the brain of experimental AD mice. Taken together, our data provide experimental evidence that $A$. caesarea may serve as potential food for treating or preventing neurodegenerative diseases.
\end{abstract}

Keywords: Amanita caesarea; Alzheimer's disease; apoptosis; oxidative stress; cholinergic transmitters

\section{Introduction}

Alzheimer's disease (AD), a genetically complex neurodegenerative condition typically associated with ageing, is characterized by a decline in cognitive function and poor prognosis [1]. Although the pathomechanism of $\mathrm{AD}$ remains largely unknown, the apoptosis of neurons has been hypothesized as one possible cause [2]. In clinics, neurons loss, deposition of amyloid protein, and formation of neurofibrillary tangles within neurons have been observed in brain regions of AD patients during neuropathological examination [3]. Mitochondria-mediated apoptosis is a pathological feature of neurons during $\mathrm{AD}$ development that is accompanied by increased production of reactive oxygen 
species (ROS) [4]. Oxidative stress in human bodies increases with age and is therefore considered an important causative factor in $\mathrm{AD}$, which also causes remarkable accumulation of amyloid- $\beta$ peptide $(\mathrm{A} \beta)[5,6]$.

Moreover, glutamate, the principle neurotransmitter in the adult central nervous system [7], inhibits the synthesis of glutathione, leading to the accumulation of ROS [8]. The neurotoxicity of glutamate in HT22 cells (mouse hippocampal neuronal cells) has been characterized and recognized as a common model for in vitro studies of neurodegenerative disease [9]. The AD mouse model established by intragastric $\mathrm{AlCl}_{3}$ administration combined with intraperitoneal injection of D-galactose (D-gal) serves as an ideal in vivo model for AD that can imitate AD-like behavior and pathological alterations [10].

Unfortunately, no satisfactory therapeutic agents are in use for AD patients. Herbs and/or fungi constitute a huge and underappreciated source of development in biopharmaceutics due to their beneficial health functions [11]. In our fungal group, a polysaccharide isolated from Sparassis crispa protects against L-glutamic acid (L-Glu) induced apoptosis in PC12 cells via the mitochondrial apoptotic pathway [12]. In L-Glu-induced apoptotic cells and the $\mathrm{AlCl}_{3}$ - and D-gal-developed $\mathrm{AD}$ mouse model, Hericium erinaceus aqueous extract displays therapeutic effects on $\mathrm{AD}$, in relation to not only mitochondria-mediated apoptosis, but also to the modulation of neurotransmitters [13]. Amanita caesarea, an edible mushroom, can be found in mixed coniferous and deciduous forests in Asia and southern Europe [14]. To date, most studies have focused on the constituent analysis of A. caesarea and its culture [15]. Recently, a polysaccharide separated from A. caesarea has been reported to exhibit strong antioxidant activities; thus, it may be a useful naturally occurring antioxidant [15]. The potentially beneficial effects of $A$. caesarea on neurodegenerative diseases, especially AD, have not yet been reported.

In the present study, L-Glu-induced HT22 apoptotic cells and D-gal- and $\mathrm{AlCl}_{3}$-induced experimental $\mathrm{AD}$ mice were used to investigate the activities of $A$. caesarea aqueous extracts (AC) on AD. Encouragingly, AC protected L-Glu-damaged HT22 cells, as evidenced by improved cell viability, a reduced proportion of apoptotic cells, restored mitochondrial function, regulated apoptosis-related protein expression and protein kinase $\mathrm{B}(\mathrm{Akt})$ /mammalian target of rapamycin (mTOR) signal pathway. Furthermore, AC improved behavioral, physiological, and biochemical indexes in experimental AD mice. Our present study suggests that $A$. caesarea may serve as a functional food for the adjuvant therapy of AD.

\section{Results}

\subsection{AC Ameliorated L-Glu-Induced Cytotoxicity and Apoptosis in HT22 Cells}

To detect the influence of AC on HT22 cell, MTT assay was used. HT22 exposed only to AC shows no obvious changes in cell viability (Figure 1A). Reductions in cell viability of over $60 \%$ were noted in 24-h L-Glu-exposed HT22 cells ( $p<0.001$; Figure 1B). A 3-h pretreatment with AC at doses of 25, 50, and $100 \mu \mathrm{g} / \mathrm{mL}$ and co-incubation with L-Glu (25 mM) for $24 \mathrm{~h}$ enhanced cell viability by $9.4 \%, 18.2 \%$, and $21.3 \%$, respectively, in HT22 cells compared with the L-Glu group $(p<0.05$; Figure 1B). Compared with L-Glu-treated cells, $100 \mu \mathrm{g} / \mathrm{mL}$ of AC pretreatment reduced the proportion of apoptotic cells around $10 \%$ after a 3h-pretreatment and 24 -h co-incubation $(27.2 \pm 0.76 \%$ vs. $17.1 \pm 0.54 \% ; p<0.01$; Figure 1C). 
A
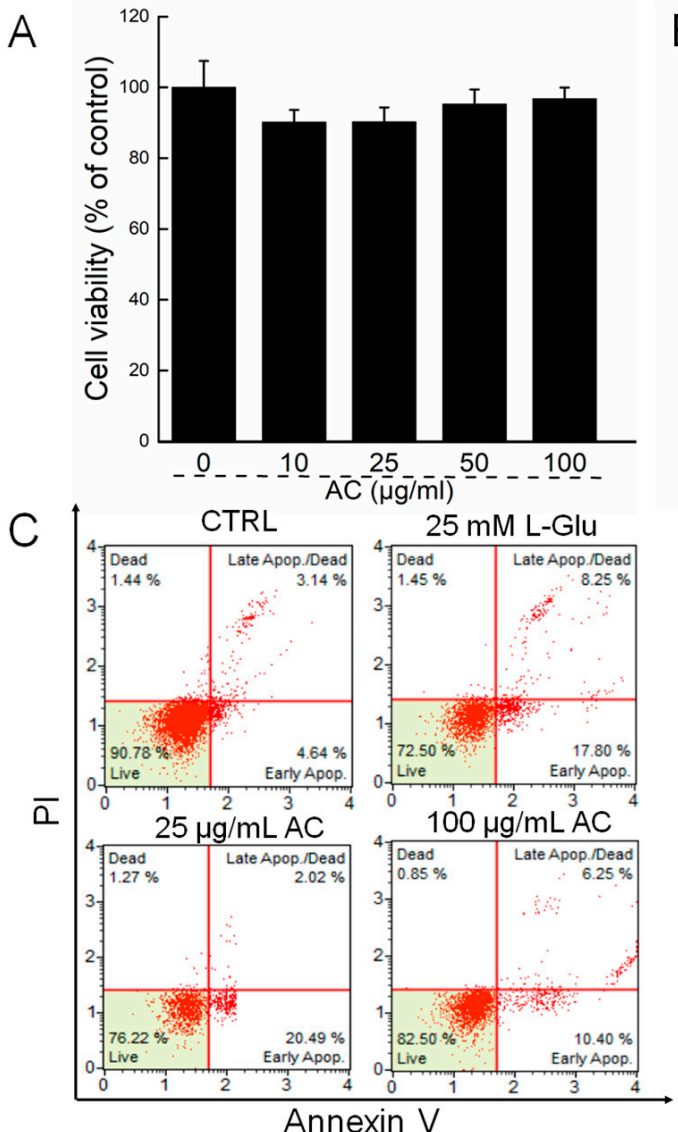
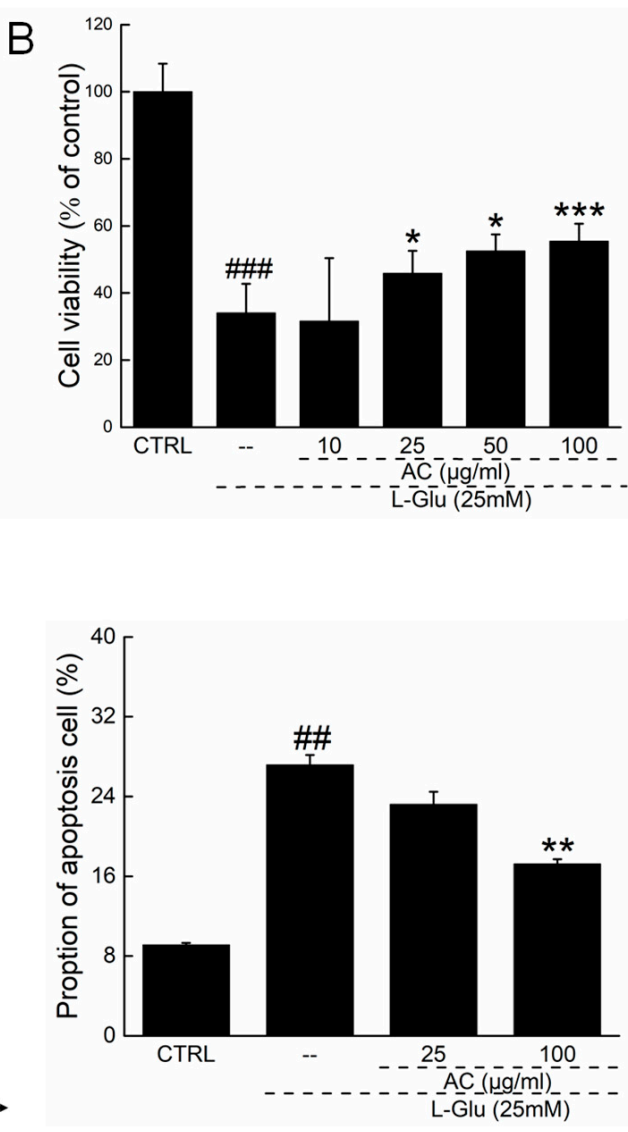

Figure 1. AC ameliorated L-Glu-induced cytotoxicity and apoptosis in HT22 cells. (A) AC has no significant influence on HT22 cell viability; (B) AC enhanced cell viability in L-Glu-damaged HT22 cells after $24 \mathrm{~h}$ co-incubation; (C) AC reduced proportion of the apoptotic cells in L-Glu-exposed HT22 cells detected by Annexin V-FITC/PI staining. Data are expressed as mean \pm S.D. $(n=6) .{ }^{\#} p<0.01$ and ${ }^{\# \# \#} p<0.001$ vs. CTRL. ${ }^{*} p<0.05,{ }^{* *} p<0.01$ and ${ }^{* * *} p<0.001$ vs. L-Glu-treated cells.

\subsection{AC Ameliorated L-Glu-Caused Mitochondrial Dysfunction in HT22 Cells}

An imbalance in mitochondrial membrane potential (MMP) characterizes the early stage of mitochondrial injury [16]. Intense red fluorescence was noted in untreated cells, indicating a healthy state (Figure 2A). In contrast, 12-h L-Glu exposure significantly decreased MMP as evidenced by the appearance of green fluorescence, which was restored by 3-h AC pretreatment and 12-h co-treatment at doses of 25 and $100 \mu \mathrm{g} / \mathrm{mL}$ (Figure 2A). Overproduction of ROS resulting in oxidative stress can be an important mediator of damage to cell structures [5]. L-Glu exposure for $12 \mathrm{~h}$ strongly enhanced the intracellular ROS level, which was inhibited by a 3-h AC pretreatment and 12-h co-treatment at doses of 25 and $100 \mu \mathrm{g} / \mathrm{mL}$, as indicated by the reduced intensity in the green fluorescence (Figure 2B). 

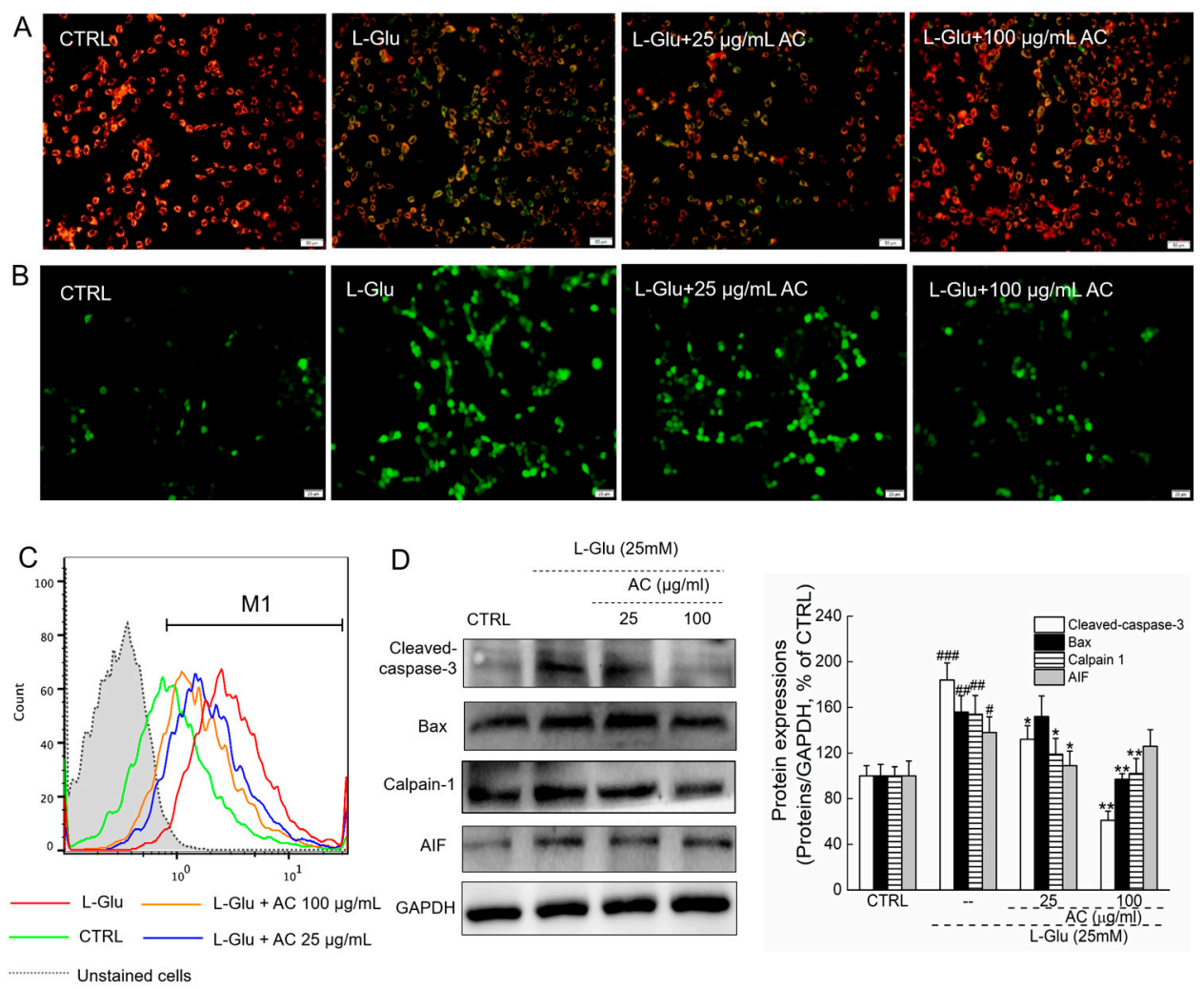

Figure 2. AC ameliorated MMP loss, intracellular ROS and $\mathrm{Ca}^{2+}$ over-production, and the apoptotic alternations on the expression levels of proteins. (A) AC pretreatment restored the disruption of MMP caused by $12-\mathrm{h}$ L-Glu exposure analyzing by $5,5^{\prime}, 6,6^{\prime}$-tetrachloro-1, $1^{\prime}, 3,3^{\prime}$-tetraethyl-imidacarbocyanine iodide staining (JC-1) $(n=6)(20 \times$; Scale bar: $25 \mu \mathrm{m}) ;(B)$ AC pretreatment inhibited the over-accumulation of intracellular ROS caused by 12-h L-Glu exposure detecting by DCFH-DA staining $(n=6)(20 \times$; Scale bar: $25 \mu \mathrm{m})$; (C) AC ameliorated the over-load of intracellular Ca ${ }^{2+}$ caused by 12-h L-Glu exposure analyzing by Fluo 4-AM staining $(n=6)$; (D) AC reduced the expression levels of cleaved caspase-3, Bax, calpain 1 and apoptosis-inducing factor (AIF) in L-Glu-exposed HT22 cells after 24-h co-incubation. Quantification data was normalized by GAPDH, expressed as percentage of CTRL and mean \pm S.D. $(n=6) .{ }^{\#} p<0.05$ and ${ }^{\# \#} p<0.01$ vs. CTRL, ${ }^{*} p<0.05$ and ${ }^{* *} p<0.01$ vs. L-Glu-treated cells.

$\mathrm{Ca}^{2+}$ overload is a key mediator of L-Glu-induced toxicity, which is associated with mitochondrial function [17]. Compared with control cells (green peak), a 12-h L-Glu exposure caused $\mathrm{Ca}^{2+}$ overload (red peak) ( $p<0.01$; Figures A1 and 2C). A 3-h AC pretreatment at doses of 25 and $100 \mu \mathrm{g} / \mathrm{mL}$ (orange and blue peak, respectively) successfully inhibited the high $\mathrm{Ca}^{2+}$ levels in HT22 cells $(p<0.05$; Figures $\mathrm{A} 1$ and $2 \mathrm{C}$ ).

Calpains and AIF are proteins that relate to mitochondrial function $[18,19]$. L-Glu enhanced the expression levels of calpains, AIF, Bax and cleaved caspase- 3 in HT22 cells $(p<0.05)$, whereas AC strongly suppressed these enhancements after 24-h co-incubation $(p<0.05$; Figure 2D).

\subsection{AC Ameliorated L-Glu-Induced Cell Injury by Akt/mTOR Pathway}

The pro-survival and anti-apoptotic Akt signaling is involved in neuronal protection [20]. In L-Glu-exposed HT22 cells, reduced expression levels of P-Akt and P-mTOR and enhanced phosphorylation activities of phosphorylation-tensin homolog deleted on chromosome ten (PTEN) were noted $(p<0.05$; Figure 3$)$. All these abnormal changes were regulated by 3 -h AC pretreatment followed by $24-\mathrm{h}$ co-imbibition ( $p<0.05$; Figure 3$)$. 

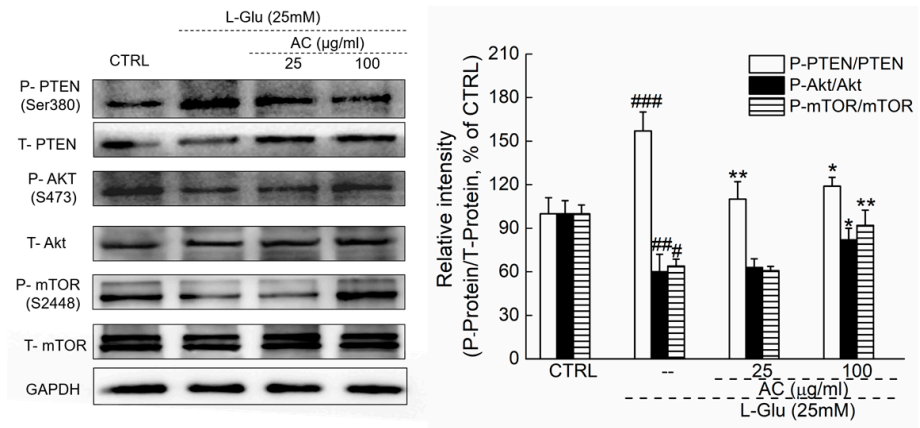

Figure 3. 3-h AC pre-exposure regulated the phosphorylation activities of PTEN, Akt and mTOR in L-Glu-exposed HT22 cells. Quantification data of the expressions of P-PTEN, P-Akt and P-mTOR were normalized by corresponding T-pTEN, T-Akt and T-mTOR. Data are expressed as mean \pm SD $(n=6)$ and analyzed using one-way ANOVA. ${ }^{\#} p<0.05,{ }^{\# \#} p<0.01$ and ${ }^{\# \#} p<0.001$ vs. CTRL, ${ }^{*} p<0.05$ and ${ }^{* *} p<0.01$ vs. L-Glu-treated cells.

\subsection{AC Improved $A D$-Like Behaviors in $\mathrm{D}$-gal and $\mathrm{AlCl}_{3}$ Induced $A D$ Mice}

In the experimental $\mathrm{AD}$ mouse model induced by $\mathrm{AlCl}_{3}$ and D-gal, the number of locomotor activities $(p<0.05$; Figure 4A) and vertical movements $(p<0.05$; Figure 4B) strongly decreased, and these effects were enhanced by a 28-day AC administration $(p<0.05$; Figure $4 \mathrm{~A}, \mathrm{~B})$. Compared with normal mice, a reduction of over $68.7 \%$ in the remaining time in the rotating test was noted in AD-like mice; in contrast, AC enhanced the remaining time by $12.3 \%$ compared with untreated AD mice $(p<0.05$; Figure 4 C). In normal mice, AC treatment alone had no significant effect on mouse movements or on the remaining time in the rotating test (Figure $4 \mathrm{~A}-\mathrm{C}$ ). To further explore the protective effects of $\mathrm{AC}$, the Morris water maze test was used to detect its influence on learning and memory in AD-like mice. Compared with other AD-like mice, AC reduced the escape latency by up to $47.1 \%(51.6 \pm 15.1 \mathrm{~s}$ vs. $96.6 \pm 15.9 \mathrm{~s} ; p<0.05$; Figure $4 \mathrm{D})$. AC alone also reduced the escape latency in normal mice $(p<0.05$; Figure $4 \mathrm{D})$. All data suggest that AC significantly improves memory and physical performance in the AD experimental mouse model.
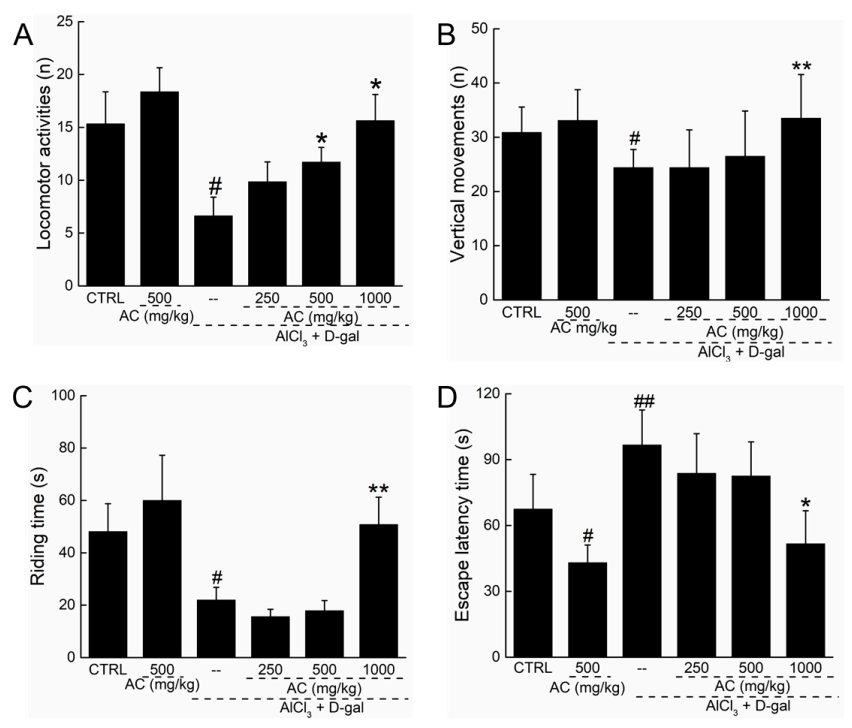

Figure 4. $\mathrm{AC}$ improves $\mathrm{AD}$-like behaviors in $\mathrm{D}$-gal and $\mathrm{AlCl}_{3}$ development $\mathrm{AD}$ mice. Compared with non-treated $\mathrm{AD}$ mice, 28-day AC administration enhanced horizontal movements(A) and vertical movements (B) in locomotor activity test; $(\mathbf{C})$ enhanced the remaining time in rotating test; (D) reduced the escape latency time in WMT. Data expressed as mean \pm S.E.M. $(n=12) .{ }^{\#} p<0.05$ and ${ }^{\# \#} p<0.01$ vs. control mice, ${ }^{*} p<0.05$ and ${ }^{* *} p<0.01$ vs. AD mice. 
2.5. AC Regulated the Levels of Acetylcholine (Ach), Acetyltransferase (ChAT), and Acetylcholine Esterase (AchE) in the Serum and Brain of AD Mice

The neurotransmitter acetylcholine is a major modulator of learning and memory [21]. AC treatment alone showed no effect on the levels of Ach, ChAT, and AchE in the serum and brain compared with normal mice (Table 1). In AD experimental mice, a significant reduction in Ach and ChAT levels $(p<0.05$; Table 1$)$ and a significant increase in AchE levels $(p<0.05$; Table 1$)$ were noted in the serum and brain of AD-like mice. A 28-day AC treatment, especially at $1000 \mathrm{mg} / \mathrm{kg}$, successfully restored all the altered levels of Ach, ChAT, and AchE in the serum and brain of AD mice $(p<0.05$; Table 1). AC therefore has the capability to reduce cholinergic dysfunction in an experimental mouse model of $\mathrm{AD}$, thereby reducing behavioral dysfunctions.

Table 1. AC regulated the levels of Ach, ChAT and AchE in the serum and brain.

\begin{tabular}{|c|c|c|c|c|c|c|c|}
\hline \multirow{3}{*}{ Groups } & \multirow{3}{*}{ Neurotransmitters } & \multirow{3}{*}{ CTRL } & \multirow{3}{*}{ AC (500 mg/kg) } & \multicolumn{4}{|c|}{$\mathrm{AlCl}_{3}+$ D-gal } \\
\hline & & & & \multirow{2}{*}{ CTRL } & \multicolumn{3}{|c|}{$\mathrm{AC}(\mathrm{mg} / \mathrm{kg})$} \\
\hline & & & & & 250 & 500 & 1000 \\
\hline \multirow{3}{*}{ Serum } & Ach $(\mu \mathrm{g} / \mathrm{mL})$ & $115.4 \pm 5.8$ & $107.2 \pm 6.6$ & $87.2 \pm 8.4^{\#}$ & $98.3 \pm 5.5$ & $89.1 \pm 3.1$ & $108.8 \pm 4.2 *$ \\
\hline & AchE (nmol/ L) & $9.7 \pm 0.2$ & $9.6 \pm 0.1$ & $11.2 \pm 0.3^{\#}$ & $10.7 \pm 0.1$ & $9.8 \pm 0.2 *$ & $9.6 \pm 0.1^{*}$ \\
\hline & ChAT (pg/mL) & $181.6 \pm 8.3$ & $195.7 \pm 23.2$ & $163.4 \pm 18.2^{\#}$ & $182.7 \pm 9.9$ & $204.1 \pm 13.7^{*}$ & $204.1 \pm 15.2$ * \\
\hline \multirow{3}{*}{ Tissue } & Ach ( $\mu \mathrm{g} / \mathrm{mgprot})$ & $2.1 \pm 0.1$ & $2.4 \pm 0.2$ & $1.3 \pm 0.1$ \#\# & $1.3 \pm 0.2$ & $1.2 \pm 0.1$ & $2.1 \pm 0.2 *$ \\
\hline & AchE (nmol/gprot) & $0.28 \pm 0.03$ & $0.21 \pm 0.02$ & $0.47 \pm 0.06^{\#}$ & $0.48 \pm 0.06$ & $0.37 \pm 0.02 *$ & $0.37 \pm 0.05^{*}$ \\
\hline & ChAT (pg/mgprot) & $6.9 \pm 0.5$ & $7.2 \pm 0.3$ & $5.0 \pm 0.1^{\#}$ & $5.1 \pm 0.6$ & $7.2 \pm 0.3^{*}$ & $7.3 \pm 0.4^{*}$ \\
\hline
\end{tabular}

28-day AC treatment strongly enhanced the levels of Ach and ChAT, and reduced the levels of AchE in serum and brain compared with non-treated AD mice. Data expressed as mean \pm S.E.M. $(n=12) .{ }^{\#} p<0.05$ and ${ }^{\# \#} p<0.01$ vs. control mice, $* p<0.05$ vs. AD mice.

\subsection{AC Modulated the Levels of Superoxide Dismutase (SOD) and ROS in the Brains of AD Mice}

Oxidative stress is responsible for cell loss and other pathologies during the development of neurodegenerative diseases [22]. AC alone showed no significant effects on the levels of SOD and ROS in brain (Figure 5). In AD experimental mice, however, a 24.6\% reduction in SOD and a $44.7 \%$ increase in ROS in the brain were noted ( $p<0.01$; Figure 5$)$, but a 28-day AC administration enhanced SOD levels $(p<0.05$; Figure 5A) and reduced ROS levels $(p<0.05$; Figure $5 \mathrm{~B})$ in the brain. The antioxidative properties of AC contribute to its neuroprotective effects.
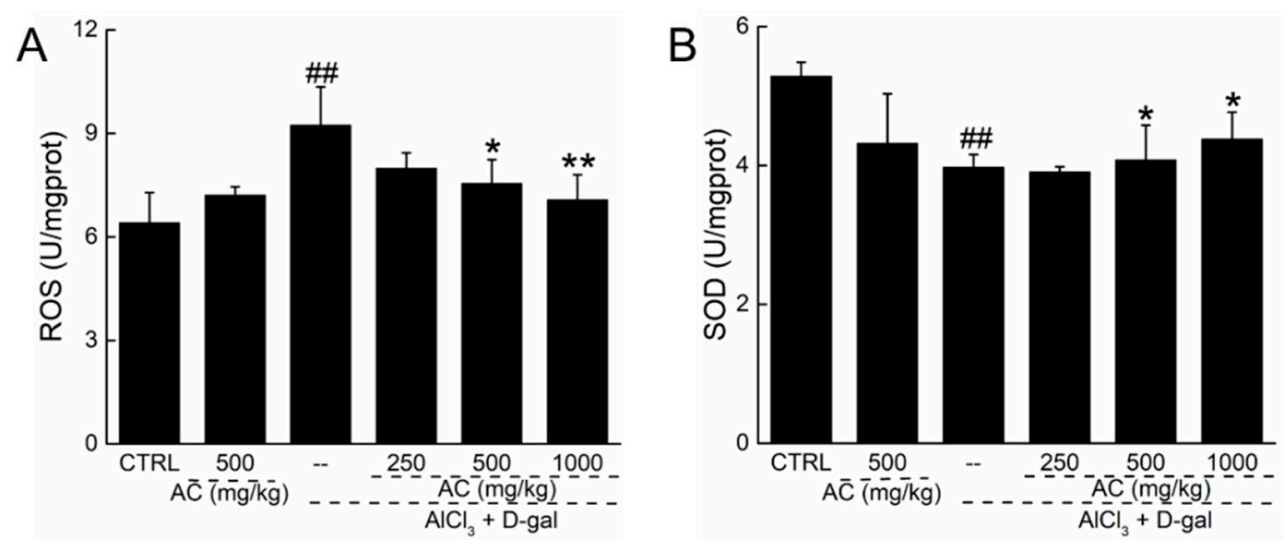

Figure 5. AC ameliorated oxidation stress in brain of AD mice. 28-day AC administration reduced the levels of ROS (A); and enhanced the levels of SOD (B) in brain of AD-like mice. Data expressed as mean \pm S.E.M. $(n=12) .{ }^{\# \#} p<0.01$ vs. control mice, ${ }^{*} p<0.05$ and ${ }^{* *} p<0.01$ vs. AD mice.

\subsection{The Effect of $A C$ on the Levels of A 1-42 in Serum and Brain of AD Mice}

The accumulation of $A \beta$ containing neuritic plaques in the brain is a neuropathological feature of $\mathrm{AD}$ [23]. AC treatment alone displayed no effects on the levels of $A \beta 1-42$ in the serum and brain 
of normal mice (Figure 6). However, low levels of $A \beta 1-42$ in serum and high levels of $A \beta 1-42$ in the brain were noted in AD mice (Figure 6). A 28-day administration of AC enhanced the A $\beta 1-42$ levels in serum by $15 \%(p<0.05$; Figure $6 \mathrm{~A})$, and reduced levels of $\mathrm{A} \beta 1-42$ in the brain by $14.3 \%(p<0.05$; Figure 6B).
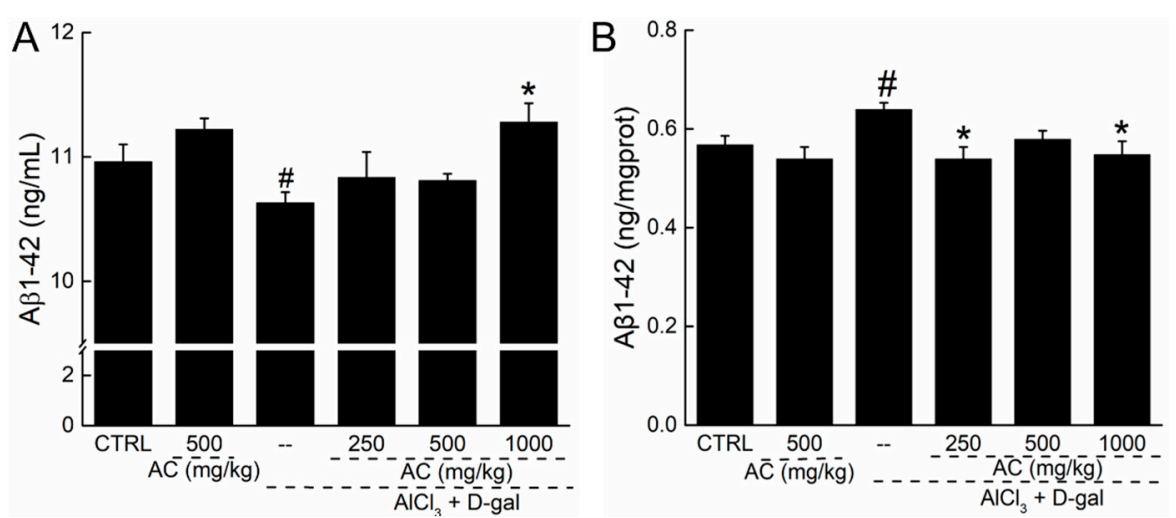

Figure 6. The effect of $A C$ on the levels of $A \beta 1-42$ in serum and brain of AD-like mice. 28-day AC administration enhanced the levels of $A \beta 1-42$ in serum (A); but reduced the levels of $A \beta 1-42$ in brain (B) of AD-like mice. Data expressed as mean \pm S.E.M. $(n=12) .{ }^{\#} p<0.05$ vs. control mice, ${ }^{*} p<0.05$ vs. AD mice.

\section{Discussion}

$\mathrm{AD}$ affects more than 40 million people worldwide, and is predicted to increase exponentially in the coming decade [24]. In the present study, we successfully confirmed the protective effects of $\mathrm{AC}$ on $\mathrm{AD}$, as suggested by the improvement in cell viability, reduction in the proportion of apoptotic cells, restoration of MMP dissipation, inhibition of ROS and $\mathrm{Ca}^{2+}$ overproduction, regulation of the expression of apoptosis-related proteins, influence of Akt/mTOR signal pathway in L-Glu-damaged HT22 cells, and the enhancement of learning and memory abilities in experimental AD mice associated with the regulation of oxidative stress and the cholinergic system.

Glutamate inhibits cysteine uptake, results in the downregulation of glutathione, and ultimately causes oxidative stress and necrotic and apoptotic cell processes. AC has been reported to show anti-oxidative effects in cells [25], which led us to further investigate its neuroprotection related to oxidative stress. Mitochondria, the centers of intracellular energy metabolism, can be affected by intracellular $\mathrm{Ca}^{2+}$ overload [26]. As $\mathrm{Ca}^{2+}$-activated non-lysosomal cysteine proteases [18], the deregulated calpain 1 activity following with the loss of $\mathrm{Ca}^{2+}$ homeostasis results in mitochondrial depolarization, cleavage of Bid and AIF [27], and ROS released from the mitochondria into the cytoplasm [18,28]. In a feedback loop, the overaccumulation of ROS in cytoplasm may further cause MMP dissipation [29]. In our present study, we found that AC not only improved MMP dissipation by reducing the raised levels of intracellular ROS and $\mathrm{Ca}^{2+}$, but also inhibited the high expression of cleaved caspase-3, calpain 1, AIF, and Bax in L-Glu-exposed HT22 cells. As one of the Bcl-2 family, Bax serves as a hallmark for mitochondrial function detection [30]. The dissipation of MMP triggers caspase-3, which is activated in the cytosol and finally executes apoptosis [31]. However, the pro-survival and anti-apoptotic Akt/mTOR signaling pathway is involved in neuronal protection through the stimulation of neuroprotective factors [32]. Akt deactivation characterizes both caspase-dependent and -independent cell death, and improves mitochondrial function by regulating the expression of the Bcl-2 family [33,34]. As reported, the accumulation of ROS activates multiple pathways including Akt signaling [35]. Activated Akt phosphorylates the downstream mTOR, which regulates cell metabolism by promoting mitochondrial biogenesis and the synthesis of proteins, lipids, and nucleotides [36]. Moreover, as a key negative regulator of Akt/mTOR signaling [37], the phosphorylation activity of PTEN was strongly reduced by 3-h AC pretreatment. Combining 
all of the data, the neuroprotective effects of AC on L-Glu damaged HT22 cells may be related to improvement in mitochondrial functioning via the modulation of Akt/mTOR signaling.

While testing the sub-acute toxicity of several carbohydrates, scientists in China first reported that injections of D-gal could induce neurological impairment in rodents [38]. Aluminum itself is neurotoxic in animals, and capable of forming a complex with $\mathrm{A} \beta$ that has more ready access to the brain, causing cerebrovascular dysregulation [39].Chronic administration of D-gal and $\mathrm{AlCl}_{3}$ leads to deterioration in cognitive and motor skills and AD-like behavior due to brain damage through various mechanisms, including oxidative stress [40,41], dysfunction of the cholinergic system [42,43], biochemical and histopathological alterations, and aggregation of $A \beta$ [39]. By improving AD-like behavior in a D-gal- and $\mathrm{AlCl}_{3}$-developed $\mathrm{AD}$-like mice model, $\mathrm{AC}$ has confirmed its potential neuroprotective properties in AD-like mice. In line with other studies, we observed elevated ROS that led to a dramatic decrease in SOD in the brain of AD mice, which was significantly improved after AC administration. An imbalance between ROS generation and termination accelerates AD progression $[44,45]$. Endogenous antioxidants such as SOD are suggested to be a first-line defense mechanism involving oxidative stress [46]. Additionally, AC elevated serum levels of $A \beta$ and decreased the expression of $A \beta$ in the brain. $A \beta$ is normally cleared from the brain into the periphery, and changes in its production or clearance can result in its accumulation in the brain, accompanied by reduced peripheral levels and the clinicopathological manifestations of $\mathrm{AD}$ [47]. As a hallmark of $\mathrm{AD}, \mathrm{A} \beta$ is responsible for spatial memory deficit and cognitive dysfunction [48], which is regulated by oxidative stress through enhancement of the amyloidogenic fragment of APP [46,49]. The data are consistent with the results obtained in HT22 cells, where the antioxidative activities of AC resulted in reducing the learning and memory deficits in AD-like mice.

In addition to oxidative stress, the impaired cholinergic functionality observed in AD is also responsible for the cognitive decline and memory loss [46]. Ach, a major modulator of learning and memory, is dynamically controlled by the synthesizing enzyme ChAT and the terminating enzyme AchE [50]. The reduced levels of Ach and ChAT were found in the brain of AD patients [51]. In our group, $H$. erinaceus has been confirmed to show protection against $\mathrm{AD}$ via dose-dependent enhancement of Ach and ChAT concentrations in both serum and the hypothalamus [13]. In the present study, AC not only enhanced the levels of Ach and ChAT, but also reduced the levels of AchE in the brains of AD-like mice, indicating that the cholinergic function has an important role in protecting against $\mathrm{AD}$. However, further investigation is needed to provide more detailed information related to cholinergic activities during AD development and AC therapy.

In conclusion, use of the L-Glu-induced HT22 apoptotic cell model and the $\mathrm{AlCl}_{3}$ - and D-gal-developed experimental AD mice model has successfully confirmed the potential neuroprotective properties of $\mathrm{AC}$ against $\mathrm{AD}$, which may be related to its modulation of oxidative stress and neurotransmitters levels, especially the cholinergic system.

\section{Materials and Methods}

\subsection{Preparation of A. caesarea Water Extract (AC)}

A. caesarea sporocarp (obtained from Yunnan province, China) was extracted in hot water at $80{ }^{\circ} \mathrm{C}$ for $3 \mathrm{~h}$ twice. In detail, $100 \mathrm{~g}$ A. caesarea was mashed, soaked in $3 \mathrm{~L}$ double distilled (D.D.)-water, heat up to $80^{\circ} \mathrm{C}$ for $3 \mathrm{~h}$, then the mixture was filtered and $3 \mathrm{~L}$ D.D.-water was added again. The supernatant fluid was collected, concentrated to $280 \mathrm{~mL}(360 \mathrm{mg} / \mathrm{mL})$, and then freeze-dried by a Freeze dryer (GENESIS, SQ25ES, VirTis, Gardiner, NY, USA). Then the powder was diluted to the concentration for the further experiments.

\subsection{Cell Culture}

HT22 cell, a mouse hippocampal neuron cell line (BNCC, 337709), was cultured in Dulbecco's Modified Eagle Medium (DMEM) supplemented with 10\% fetal bovine serum (FBS), 100 units /mL 
penicillin and $100 \mu \mathrm{g} / \mathrm{mL}$ of streptomycin at $37{ }^{\circ} \mathrm{C}$ in an atmosphere containing $5 \% \mathrm{CO}_{2}$ and $95 \%$ air. All the cell culture materials were purchased from BRL (Grand Island, NY, USA).

\subsection{Cell Viability Assay}

HT22 cells were seeded into the 96-well plates at $5 \times 10^{3}$ cells/well and pre-treated with AC from 0 to $100 \mu \mathrm{g} / \mathrm{mL}$ for $3 \mathrm{~h}$, and then $25 \mathrm{mM}$ of L-Glu (Sigma-Aldrich, St. Louis, MO, USA) were added and co-cultured with AC for another $24 \mathrm{~h}$. AC was diluted with basic medium to final concentration. The final concentration of serum was kept at $1 \%$ in both 96 -well plates and 6-well plates. $10 \mu \mathrm{L}$ of 3-(4,5-dimethylthiazol-2-yl)-2,5-diphenyltetrazolium bromide (MTT) at the final concentration of $0.5 \mathrm{mg} / \mathrm{mL}$ was added and reacted with the living cells. After the 4-h incubation, the supernatant was removed, and $200 \mu \mathrm{L}$ of DMSO were added. The optical density at wavelength of $570 \mathrm{~nm}$ was read by a Synergy ${ }^{\mathrm{TM} 4}$ Microplate Reader (BioTek Instruments, Winooski, VT, USA).

\subsection{Cell Apoptosis Assay}

HT22 cells were pretreated with AC at doses of 25 and $100 \mu \mathrm{g} / \mathrm{mL}$ for $3 \mathrm{~h}$, and then co-incubated with $25 \mathrm{mM}$ of L-Glu for another $24 \mathrm{~h}$. Then cells were digested with trypsin, and washed with phosphate-buffer saline (PBS) twice. Then cells were resuspended with PBS and incubated with propidium iodide (PI) and Annexin V for $20 \mathrm{~min}$ at room temperature in darkness. The intensity of fluorescence was measured utilizing Muse ${ }^{\mathrm{TM}}$ Cell Analyzer from Millipore (Billerica, MA, USA) following manufacturer's instructions.

\subsection{Mitochondrial Transmembrane Potential (MMP) Measurement}

JC-1 (Calbiochem, San Diego, CA, USA) staining was used to detect the changes in MMP. Dissolve the dye with basic medium, and warm it up in a water bath at $37^{\circ} \mathrm{C}$ with light exposure. HT22 cells were pre-incubated with 25 and $100 \mu \mathrm{g} / \mathrm{mL}$ of $\mathrm{AC}$ for $3 \mathrm{~h}$, and then co-incubated with $25 \mathrm{mM}$ of L-Glu for another $12 \mathrm{~h}$. The cells were washed with warmed PBS twice then incubated with dyes. After 15-min staining of $2 \mu \mathrm{mol} / \mathrm{L}$ of JC-1 in darkness at $37^{\circ} \mathrm{C}$, cells were washed with PBS for three times. The red and green fluorescence was recorded with fluorescence microscope $(20 \times$; CCD camera, TE2000, Nikon, Tokyo, Japan). The experiment was repeated for six times.

\subsection{Intracellular ROS Measurement}

HT22 cells were pre-incubated with AC (25 and100 $\mu \mathrm{g} / \mathrm{mL})$ for $3 \mathrm{~h}$, and followed by a 12-h co-culture with $25 \mathrm{mM}$ of L-Glu. Fluorescent probe dye was diluted with basic medium and warmed up in a water bath at $37^{\circ} \mathrm{C}$ Cells were stained with $10 \mu \mathrm{M}$ of $2^{\prime}-7^{\prime}$-dichlorodihydrofluorescein diacetate (DCFH-DA, Sigma-Aldrich, St. Louis, MO, USA) for $15 \mathrm{~min}$ in darkness at $37^{\circ} \mathrm{C}$, and then washed with PBS for three times. The green fluorescence, which reflects the intracellular ROS level, was recorded by a Nikon Eclipse TE 2000-S fluorescence microscope (Nikon, Japan).

\subsection{Intracellular $\mathrm{Ca}^{2+}$ Measurement}

Fluo-4-AM (Molecular Probes, Eugene, OR, USA) dye was diluted with DMSO to the concentration of $2 \mathrm{mM}, \mathrm{HT} 22$ cells were seeded into 6-well plates at the density of $2 \times 10^{5}$ cells $/$ well, and pre-treated with AC at 25 and $100 \mu \mathrm{g} / \mathrm{mL}$ for $3 \mathrm{~h}$, followed by 12 -h co-culture with $25 \mathrm{mM}$ of L-Glu. Cells were digested with trypsin and centrifuge for $3 \mathrm{~min}$ at $1200 \mathrm{r}$. Collected cells were resuspended with Hank's Balanced Salt Solution (HBBS) containing $2 \mu$ M Fluo-4-AM. After 15-min staining, cells were washed with HBSS for three times, then subjected to flowcytometric analysis using the Muse ${ }^{\mathrm{TM}}$ Cell Analyzer (Millipore, Billerica, MA, USA). 


\subsection{Western Blot}

HT22 cells were pre-treated with AC at 25 and $100 \mu \mathrm{g} / \mathrm{mL}$ for $3 \mathrm{~h}$ followed by $24-\mathrm{h}$ co-incubation with $25 \mathrm{mM}$ of L-Glu. Then cells were harvested and lysed with RIPA buffer (Sigma-Aldrich, St. Louis, MO, USA) containing 1\% protease inhibitor cocktail (Sigma-Aldrich, St. Louis, MO, USA) and 2\% Phenylmethanesulfonyl fluoride (PMSF) (Sigma-Aldrich, St. Louis, MO, USA). BCA protein assay kit was used to determine the concentration of the lysed cell protein. $40 \mu \mathrm{g}$ of protein lysates were separated by $10-12 \%$ SDS-PAGE and transferred onto polyvinylidene difluoride (PVDF) membranes $(0.45 \mu \mathrm{m}$, Merck Millipore, Billerica, MA, USA). Then the membranes were blocked by $5 \%$ bovine serum albumin (BSA) for $2 \mathrm{~h}$ at room temperature, followed by 12-h incubation of primary antibodies at $4{ }^{\circ} \mathrm{C}$ : phosphor (P)-mTOR (S2448) (ab109268), total (T)-mTOR (ab83495), P-Akt (S473) (ab18206), T-Akt (ab106693), cleaved-caspase 3 (ab2302), Bax (ab32503), and Glyceraldehyde-3-phosphate dehydrogenase (GAPDH; ab181602) (Abcam, Cambridge, MA, USA) at $4{ }^{\circ} \mathrm{C}$ overnight at, calpain 1 (bs-1099R), AIF (bs-0037R), phospho-PTEN (Ser380) (bs-3350R), PTEN (bs-0686r) (Bioss Inc., Beijing, China). Horseradish peroxidase (HRP)-conjugated secondary antibody was used to bind the primary antibody at $4{ }^{\circ} \mathrm{C}$ for $4 \mathrm{~h}$. The protein bands were visualized using an ECL kit (Merck Millipore, Billerica, MA, USA), and the membranes were scanned utilizing an imaging system (BioSpectrum600). The pixel density was quantified by Image J software (National Institutes of Health, Bethesda, MD, USA).

\subsection{The Establishment of AD Mouse Model and Drug Treatment Process}

The study was approved by the Institution Animal Ethics Committee of Jilin University, and all experiments were carried out in accordance with the Institutional guidelines on the care and use of experimental animals. BALB/c mice (6-8 weeks; $18-20 \mathrm{~g}$ ) purchased from Norman Bethune University of Medical Science, Jilin University, Changchun, Jilin, China (SCXK(JI)-2011-0003) were maintained on a standard 12-h:12-h light/dark cycle at $23 \pm 1{ }^{\circ} \mathrm{C}$. Food and water were fed autoclaved standard chow and ad libitum.

The process of establishing the AD mouse model and the drug administration was shown in Figure 7. Generally, mice were randomly divided into 6 groups $(n=20 /$ group $)$. The model mice and AC-treated mice were intraperitoneally (i.p.) injected with $120 \mathrm{mg} / \mathrm{kg}$ of D-gal (Sigma-Aldrich, St. Louis, MO, USA) and intragastrically (i.g.) administrated with $20 \mathrm{mg} / \mathrm{kg}$ of $\mathrm{AlCl}_{3}$ (Sigma-Aldrich, St. Louis, MO, USA) once a day for 56 days. From the 29 th day, AC-treated mice were intragastrically treated with 250, 500 and $1000 \mathrm{mg} / \mathrm{kg}$ of AC everyday; meanwhile, model mice were intragastrically treated with D.D. water. Control mice were intraperitoneally and intragastrically treated with saline throughout the whole experiment. AC single treated mice were intraperitoneally and intragastrically treated with saline throughout the whole experiment and intragastrically treated with $500 \mathrm{mg} / \mathrm{kg}$ of AC from the 29th day.

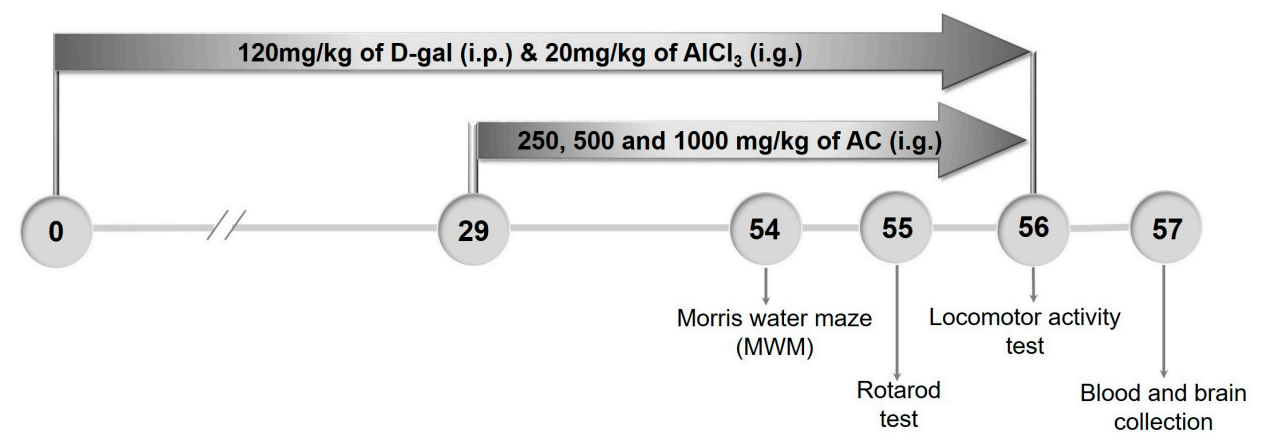

Figure 7. Schematic of experiments. The AD mouse model was established by given $\mathrm{AlCl}_{3}(20 \mathrm{mg} / \mathrm{kg}$, i.g.) and D-gal (120 mg/kg i.p.) daily for 56 days. From the 29 th day, the mice were given AC at doses of 250,500 and $1000 \mathrm{mg} / \mathrm{kg}$ daily for 28 days. Behavioral tests were performed starting from the 54th day. 


\subsection{Behavioral Tests}

Locomotor activity test. Each mouse was separately placed into a dark square of the multichannel activity box for testing the independent activity of animals (ZZ-6, Chengdu Techman Software Co., Ltd., Chengdu, China) to observe their reaction in the darkness. Mice were given two minutes to adapt the environment before the formal test. The horizontal and vertical activities within 5 min were recorded.

Rotarod performance test. The rotating rod test reflects the neurological deficits of mice. Mice were pre-trained for $1 \mathrm{~min}$ for three times before the formal experiment. For the analysis, mice were placed on the rotating cylinder (ZB-200, Chengdu Techman Software Co., Ltd., Chengdu, China) with the speed of $20 \mathrm{rpm}$, and the time when mice fell off was recorded.

Morris water maze test. The Morris water maze test (MWM) was used to evaluate the learning and memory abilities of mice. The maze was a circular pool filled with $10 \mathrm{~cm}$ depth water $\left(24-26^{\circ} \mathrm{C}\right)$ containing $1 \mathrm{~L}$ of milk. Mice were trained quietly with the same position of operator for five days before the formal test. The latency from immersion of mice into the pool to escape onto the hidden platform was recorded. On the test day, mice were subjected to a $120 \mathrm{~s}$ probe trial in which the platform was obscure from the pool. The time spent within 120 s probe test time in target quadrant was recorded.

\subsection{Biochemical Analysis}

After behavioral tests, blood was sampled from caudal vein of each mouse, and then, mice were anesthetized and decapitated quickly. Brains of mice were removed immediately and placed onto ice. The brain was homogenized in ice-cold PBS (w/v: 1-5) and the protein concentration was determined using BCA assay kit.

The levels of Ach, AchE, ChAT and A $\beta$ 1-42 in serum and brain were measured by enzyme-linked immunosorbent assay (ELISA) according to the procedures provided by the related assay kits (Nanjing Jiancheng Bioengineering Institute, Nanjing, China). The levels of ROS and SOD in brain were measured by ELISA kits (Nanjing Jiancheng Bioengineering Institute, Nanjing, China).

\subsection{Statistical Analysis}

Data were expressed as mean \pm S.D. in cells, and mean \pm S.E.M in mouse experiments. SPSS 16.0 software (IBM Corporation, Armonk, NY, USA) was used to analyze the data. The statistical significance was determined by the One-way analysis of variance (ANOVA) followed by post hoc multiple comparisons (Dunn's test). The value of $p<0.05$ was considered significant.

Acknowledgments: This work was supported by Science and Technology Development Program of Jilin Province in China (Grant No. 20160520036JH), and Key Scientific and Technological Project of Jilin Province in China (Grant No. 20160204029YY and 20150203002NY), and Project Approved by Development and Reform Commission of Jilin Province (Grant No. 2016C023).

Author Contributions: Di Wang and Xia Chen designed the experiments; Zhiping Li, Wenqian Lu, Zeyu Li, Xin Guan, Shun Zhang performed the experiments; Zhiping Li and Xia Chen processed data; Zhiping Li and Di Wang wrote the paper; Di Wang and Xia Chen revised the paper.

Conflicts of Interest: The authors declare no conflict of interest.

\section{Abbreviations}

$\begin{array}{ll}\text { Ach } & \text { Acetylcholine } \\ \text { AchE } & \text { Acetylcholine esterase } \\ \text { AC } & \text { A. caesarea water extracts } \\ \text { AD } & \text { Alzheimer's disease } \\ \text { Akt } & \text { Protein kinase B } \\ \text { ANOVA } & \text { A one-way analysis of variance } \\ \text { A } \beta & \text { Amyloid beta } \\ \text { ChAT } & \text { Choline acetyltransferase } \\ \text { D-gal } & \text { D-galactose } \\ \text { ELISA } & \text { Enzyme-linked immunosorbent assay }\end{array}$




$\begin{array}{ll}\text { GAPDH } & \text { Glyceraldehyde-3-phosphate dehydrogenase } \\ \text { L-Glu } & \text { L-glutamic acid } \\ \text { MMP } & \text { Mitochondrial membrane potential } \\ \text { mTOR } & \text { Mammalian target of rapamycin } \\ \text { ROS } & \text { Reactive oxygen species } \\ \text { SOD } & \text { Superoxide dismutase }\end{array}$

\section{Appendix}

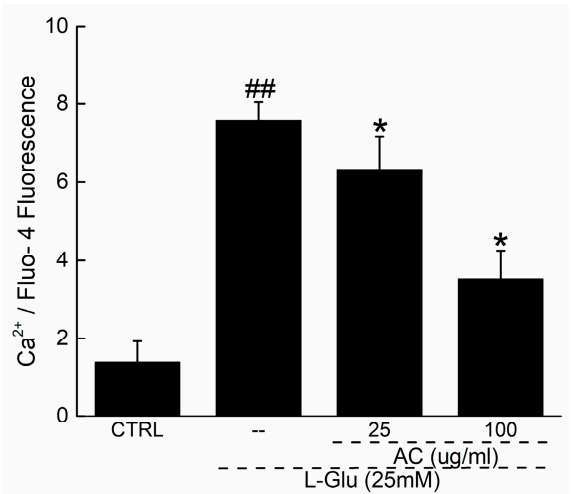

Figure A1. Effect of AC on the over-load of intracellular $\mathrm{Ca}^{2+}$ caused by 12-h L-Glu. Quantitative analysis of $\mathrm{Ca}^{2+}$ values of fluorescence intensity obtained from Figure $2 \mathrm{C}(n=6) .{ }^{\# \#} p<0.01 \mathrm{vs}$. CTRL, * $p<0.05$ vs. L-Glu-treated cells.

\section{References}

1. Rygiel, K. Novel strategies for Alzheimer's disease treatment: An overview of anti-amyloid beta monoclonal antibodies. Indian J. Pharmacol. 2016, 48, 629-636. [CrossRef] [PubMed]

2. Rosello, A.; Warnes, G.; Meier, U.C. Cell death pathways and autophagy in the central nervous system and its involvement in neurodegeneration, immunity and central nervous system infection: To die or not to die-that is the question. Clin. Exp. Immunol. 2012, 168, 52-57. [CrossRef] [PubMed]

3. Castellani, R.J. Vascular dementia and alzheimer's disease: A waning dichotomy. J. Alzheimer's Dis. 2007, 12, 343-344. [CrossRef]

4. Faizi, M.; Seydi, E.; Abarghuyi, S.; Salimi, A.; Nasoohi, S.; Pourahmad, J. A search for mitochondrial damage in Alzheimer's disease using isolated rat brain mitochondria. Iran. J. Pharm. Res. 2016, 15, 185-195. [PubMed]

5. Valko, M.; Leibfritz, D.; Moncol, J.; Cronin, M.T.; Mazur, M.; Telser, J. Free radicals and antioxidants in normal physiological functions and human disease. Int. J. Biochem. Cell Biol. 2007, 39, 44-84. [CrossRef] [PubMed]

6. Smith, D.G.; Cappai, R.; Barnham, K.J. The redox chemistry of the Alzheimer's disease amyloid beta peptide. Biochim. Biophys. Acta 2007, 1768, 1976-1990. [CrossRef] [PubMed]

7. Lai, T.W.; Zhang, S.; Wang, Y.T. Excitotoxicity and stroke: Identifying novel targets for neuroprotection. Prog. Neurobiol. 2014, 115, 157-188. [CrossRef] [PubMed]

8. Luo, P.; Fei, F.; Zhang, L.; Qu, Y.; Fei, Z. The role of glutamate receptors in traumatic brain injury: Implications for postsynaptic density in pathophysiology. Brain Res. Bull. 2011, 85, 313-320. [CrossRef] [PubMed]

9. Murphy, T.H.; Miyamoto, M.; Sastre, A.; Schnaar, R.L.; Coyle, J.T. Glutamate toxicity in a neuronal cell line involves inhibition of cystine transport leading to oxidative stress. Neuron 1989, 2, 1547-1558. [CrossRef]

10. Luo, Y.; Niu, F.; Sun, Z.; Cao, W.; Zhang, X.; Guan, D.; Lv, Z.; Zhang, B.; Xu, Y. Altered expression of abeta metabolism-associated molecules from D-galactose/ALCL 3 induced mouse brain. Mech. Ageing Dev. 2009, 130, 248-252. [CrossRef] [PubMed]

11. Lindequist, U.; Niedermeyer, T.H.; Julich, W.D. The pharmacological potential of mushrooms. Evid.-Based Complement. Altern. Med. 2005, 2, 285-299. [CrossRef] [PubMed]

12. Hu, S.; Wang, D.; Zhang, J.; Du, M.; Cheng, Y.; Liu, Y.; Zhang, N.; Wang, D.; Wu, Y. Mitochondria related pathway is essential for polysaccharides purified from sparassis crispa mediated neuroprotection against glutamate-induced toxicity in differentiated pc12 cells. Int. J. Mol. Sci. 2016, 17, 133. [CrossRef] [PubMed] 
13. Zhang, J.; An, S.; Hu, W.; Teng, M.; Wang, X.; Qu, Y.; Liu, Y.; Yuan, Y.; Wang, D. The neuroprotective properties of hericium erinaceus in glutamate-damaged differentiated pc12 cells and an Alzheimer's disease mouse model. Int. J. Mol. Sci. 2016, 17, 1810. [CrossRef] [PubMed]

14. Dogan, H.H.; Akbas, G. Biological activity and fatty acid composition of caesar's mushroom. Pharm. Biol. 2013, 51, 863-871. [CrossRef] [PubMed]

15. Zhu, Y.; Ding, X.; Wang, M.; Hou, Y.; Hou, W.; Yue, C. Structure and antioxidant activity of a novel polysaccharide derived from Amanita caesarea. Mol. Med. Rep. 2016, 14, 3947-3954. [CrossRef] [PubMed]

16. Ravindran, S.; Swaminathan, K.; Ramesh, A.; Kurian, G.A. Nicorandil attenuates neuronal mitochondrial dysfunction and oxidative stress associated with murine model of vascular calcification. Acta Neurobiol. Exp. 2017, 77, 57-67.

17. Kritis, A.A.; Stamoula, E.G.; Paniskaki, K.A.; Vavilis, T.D. Researching glutamate-Induced cytotoxicity in different cell lines: A comparative/collective analysis/study. Front. Cell. Neurosci. 2015, 9, 91. [CrossRef] [PubMed]

18. Goll, D.E.; Thompson, V.F.; Li, H.; Wei, W.; Cong, J. The calpain system. Physiol. Rev. 2003, 83, 731-801. [CrossRef] [PubMed]

19. Polster, B.M. Aif, reactive oxygen species, and neurodegeneration: A “complex" problem. Neurochem. Int. 2013, 62, 695-702. [CrossRef] [PubMed]

20. Heras-Sandoval, D.; Perez-Rojas, J.M.; Hernandez-Damian, J.; Pedraza-Chaverri, J. The role of pi3k/akt/mtor pathway in the modulation of autophagy and the clearance of protein aggregates in neurodegeneration. Cell. Signal. 2014, 26, 2694-2701. [CrossRef] [PubMed]

21. Gais, S.; Schonauer, M. Untangling a cholinergic pathway from wakefulness to memory. Neuron 2017, 94, 696-698. [CrossRef] [PubMed]

22. Losada-Barreiro, S.; Bravo-Diaz, C. Free radicals and polyphenols: The redox chemistry of neurodegenerative diseases. Eur. J. Med. Chem. 2017, 133, 379-402. [CrossRef] [PubMed]

23. Takahashi, R.H.; Nagao, T.; Gouras, G.K. Plaque formation and the intraneuronal accumulation of beta-amyloid in alzheimer's disease. Pathol. Int. 2017, 67, 185-193. [CrossRef] [PubMed]

24. Esquerda-Canals, G.; Montoliu-Gaya, L.; Guell-Bosch, J.; Villegas, S. Mouse models of alzheimer's disease. J. Alzheimer's Dis. 2017, 57, 1171-1183. [CrossRef] [PubMed]

25. Sarikurkcu, C.; Tepe, B.; Semiz, D.K.; Solak, M.H. Evaluation of metal concentration and antioxidant activity of three edible mushrooms from mugla, turkey. Food Chem. Toxicol. 2010, 48, 1230-1233. [CrossRef] [PubMed]

26. Feissner, R.F.; Skalska, J.; Gaum, W.E.; Sheu, S.S. Crosstalk signaling between mitochondrial $\mathrm{Ca}^{2+}$ and ROS. Front. Biosci. 2009, 14, 1197-1218. [CrossRef]

27. Cregan, S.P.; Dawson, V.L.; Slack, R.S. Role of aif in caspase-dependent and caspase-independent cell death. Oncogene 2004, 23, 2785-2796. [CrossRef] [PubMed]

28. Bernardi, P.; Rasola, A. Calcium and cell death: The mitochondrial connection. Sub-Cell. Biochem. 2007, 45, 481-506.

29. Tang, X.-Q.; Feng, J.-Q.; Chen, J.; Chen, P.-X.; Zhi, J.-L.; Cui, Y.; Guo, R.-X.; Yu, H.-M. Protection of oxidative preconditioning against apoptosis induced by $\mathrm{H}_{2} \mathrm{O}_{2}$ in pc12 cells: Mechanisms via mmp, ros, and bcl-2. Brain Res. 2005, 1057, 57-64. [CrossRef] [PubMed]

30. Gross, A.; Katz, S.G. Non-apoptotic functions of bcl-2 family proteins. Cell Death Differ. 2017, 24, 1348-1358. [CrossRef] [PubMed]

31. Chen, J.X.; Yan, S.D. Pathogenic role of mitochondrial amyloid-beta peptide. Expert Rev. Neurother. 2007, 7, 1517-1525. [CrossRef] [PubMed]

32. Romero-Leguizamon, C.R.; Ramirez-Latorre, J.A.; Mora-Munoz, L.; Guerrero-Naranjo, A. Signaling pathways mtor and akt in epilepsy. Rev. Neurol. 2016, 63, 33-41. [PubMed]

33. Ricciardi, M.R.; Mirabilii, S.; Licchetta, R.; Piedimonte, M.; Tafuri, A. Targeting the akt, gsk-3, bcl-2 axis in acute myeloid leukemia. Adv. Biol. Regul. 2017. [CrossRef] [PubMed]

34. Luo, H.R.; Hattori, H.; Hossain, M.A.; Hester, L.; Huang, Y.; Lee-Kwon, W.; Donowitz, M.; Nagata, E.; Snyder, S.H. Akt as a mediator of cell death. Proc. Natl. Acad. Sci. USA 2003, 100, 11712-11717. [CrossRef] [PubMed]

35. Zhang, J.; Wang, X.; Vikash, V.; Ye, Q.; Wu, D.; Liu, Y.; Dong, W. ROS and ROS-mediated cellular signaling. Oxidative Med. Cell. Longev. 2016, 2016, 4350965. [CrossRef] [PubMed]

36. Laplante, M.; Sabatini, D.M. Mtor signaling at a glance. J. Cell Sci. 2009, 122, 3589-3594. [CrossRef] [PubMed] 
37. Li, H.H.; Lin, S.L.; Huang, C.N.; Lu, F.J.; Chiu, P.Y.; Huang, W.N.; Lai, T.J.; Lin, C.L. Mir-302 attenuates amyloid-beta-induced neurotoxicity through activation of akt signaling. J. Alzheimer's Dis. 2016, 50, 1083-1098. [CrossRef] [PubMed]

38. Zhang, X.; Li, W.B.; Zhang, B.L. Biochemical changes in D-galactose induced subacute toxicity and mimetic aging in mice. Chin. J. Pharm. Toxicol. 1990, 4, 309-310.

39. Banks, W.A.; Niehoff, M.L.; Drago, D.; Zatta, P. Aluminum complexing enhances amyloid beta protein penetration of blood-brain barrier. Brain Res. 2006, 1116, 215-221. [CrossRef] [PubMed]

40. Lu, J.; Zheng, Y.L.; Luo, L.; Wu, D.M.; Sun, D.X.; Feng, Y.J. Quercetin reverses d-galactose induced neurotoxicity in mouse brain. Behav. Brain Res. 2006, 171, 251-260. [CrossRef] [PubMed]

41. Pratico, D.; Uryu, K.; Sung, S.; Tang, S.; Trojanowski, J.Q.; Lee, V.M. Aluminum modulates brain amyloidosis through oxidative stress in app transgenic mice. FASEB J. 2002, 16, 1138-1140. [CrossRef] [PubMed]

42. Xiao, F.; Li, X.G.; Zhang, X.Y.; Hou, J.D.; Lin, L.F.; Gao, Q.; Luo, H.M. Combined administration of d-galactose and aluminium induces alzheimer-like lesions in brain. Neurosci. Bull. 2011, 27, 143-155. [CrossRef] [PubMed]

43. Kumar, A.; Dogra, S.; Prakash, A. Protective effect of curcumin (curcuma longa), against aluminium toxicity: Possible behavioral and biochemical alterations in rats. Behav. Brain Res. 2009, 205, 384-390. [CrossRef] [PubMed]

44. Aliev, G. Oxidative stress induced-metabolic imbalance, mitochondrial failure, and cellular hypoperfusion as primary pathogenetic factors for the development of alzheimer disease which can be used as a alternate and successful drug treatment strategy: Past, present and future. CNS Neurol. Disord. Drug Targets 2011, 10, 147-148. [PubMed]

45. Christen, Y. Oxidative stress and alzheimer disease. Am. J. Clin. Nutr. 2000, 71, 621s-629s. [PubMed]

46. Islam, M.T. Oxidative stress and mitochondrial dysfunction-linked neurodegenerative disorders. Neurol. Res. 2017, 39, 73-82. [CrossRef] [PubMed]

47. Fei, M.; Jianghua, W.; Rujuan, M.; Wei, Z.; Qian, W. The relationship of plasma abeta levels to dementia in aging individuals with mild cognitive impairment. J. Neurol. Sci. 2011, 305, 92-96. [CrossRef] [PubMed]

48. Wei, H.; Gao, Z.; Zheng, L.; Zhang, C.; Liu, Z.; Yang, Y.; Teng, H.; Hou, L.; Yin, Y.; Zou, X. Protective effects of fucoidan on a $\beta 25-35$ and d-gal-induced neurotoxicity in pc12 cells and D-gal-induced cognitive dysfunction in mice. Mar. Drugs 2017, 15, 77. [CrossRef] [PubMed]

49. Weidemann, A.; Paliga, K.; Durrwang, U.; Reinhard, F.B.; Schuckert, O.; Evin, G.; Masters, C.L. Proteolytic processing of the alzheimer's disease amyloid precursor protein within its cytoplasmic domain by caspase-like proteases. J. Biol. Chem. 1999, 274, 5823-5829. [CrossRef] [PubMed]

50. Ferreira-Vieira, T.H.; Guimaraes, I.M.; Silva, F.R.; Ribeiro, F.M. Alzheimer's disease: Targeting the cholinergic system. Curr. Neuropharmacol. 2016, 14, 101-115. [CrossRef] [PubMed]

51. Farkas, E.; Luiten, P.G.M. Cerebral microvascular pathology in aging and alzheimer's disease. Prog. Neurobiol. 2001, 64, 575-611. [CrossRef]

(C) 2017 by the authors. Licensee MDPI, Basel, Switzerland. This article is an open access article distributed under the terms and conditions of the Creative Commons Attribution (CC BY) license (http:// creativecommons.org/licenses/by/4.0/). 